\title{
Article \\ Precious-Metal-Decorated Chromium(IV) Oxide Nanowires as Efficient Catalysts for 2,4-Toluenediamine Synthesis
}

\author{
Viktória Hajdu ${ }^{1}$, Alexandra Jakab-Nácsa ${ }^{1,2}$, Gábor Muránszky ${ }^{1}$, István Kocserha ${ }^{3}$, Béla Fiser ${ }^{1,4} \oplus$, \\ Tibor Ferenczi ${ }^{5}$, Miklós Nagy ${ }^{1, *}$, Béla Viskolcz ${ }^{1}$ (1) and László Vanyorek ${ }^{1, *}$ \\ 1 Institute of Chemistry, University of Miskolc, Miskolc-Egyetemváros, 3515 Miskolc, Hungary; \\ kemviki@uni-miskolc.hu (V.H.); alexandra.nacsa@borsodchem.eu (A.J.-N.); kemmug@uni-miskolc.hu (G.M.); \\ kemfiser@uni-miskolc.hu (B.F.); bela.viskolcz@uni-miskolc.hu (B.V.) \\ 2 Wanhua-Borsodchem, 1 Bolyai tér, 3700 Kazincbarcika, Hungary \\ 3 Institute of Ceramics and Polymer Engineering, University of Miskolc, Miskolc-Egyetemváros, \\ 3515 Miskolc, Hungary; istvan.kocserha@uni-miskolc.hu \\ 4 Ferenc Rákóczi II. Transcarpathian Hungarian Institute, UA-90200 Beregszász, Transcarpathia, Ukraine \\ 5 Institute of Metallurgy, University of Miskolc, Miskolc-Egyetemváros, 3515 Miskolc, Hungary; \\ femft@uni-miskolc.hu \\ * Correspondence: nagy.miklos@uni-miskolc.hu (M.N.); kemvanyi@uni-miskolc.hu (L.V.)
}

check for updates

Citation: Hajdu, V.; Jakab-Nácsa, A.; Muránszky, G.; Kocserha, I.; Fiser, B.; Ferenczi, T.; Nagy, M.; Viskolcz, B.; Vanyorek, L. Precious-MetalDecorated Chromium(IV) Oxide Nanowires as Efficient Catalysts for 2,4-Toluenediamine Synthesis. Int. J. Mol. Sci. 2021, 22, 5945. https:// doi.org/10.3390/ijms22115945

Academic Editor: Mihai V. Putz

Received: 29 April 2021

Accepted: 29 May 2021

Published: 31 May 2021

Publisher's Note: MDPI stays neutral with regard to jurisdictional claims in published maps and institutional affiliations.

Copyright: (c) 2021 by the authors. Licensee MDPI, Basel, Switzerland. This article is an open access article distributed under the terms and conditions of the Creative Commons Attribution (CC BY) license (https:// creativecommons.org/licenses/by/ $4.0 /)$.

\begin{abstract}
The catalytic hydrogenation of 2,4-dinitrotoluene (DNT) to 2,4-toluenediamine (TDA) is a key step in the production of polyurethanes; therefore, the development of efficient hydrogenation catalysts for industrial use is of paramount importance. In the present study, chromium(IV) oxide nanowires were decorated by palladium and platinum nanoparticles in a one-step, simple, and fast preparation method to yield highly efficient hydrogenation catalysts for immediate use. The nanoparticles were deposited onto the surface of $\mathrm{CrO}_{2}$ nanowires by using ultrasonic cavitation and ethanol as a reduction agent. Beneficially, the catalyst became catalytically active right at the end of the preparation and no further treatment was necessary. The activity of the Pd- and Pt-decorated $\mathrm{CrO}_{2}$ catalysts were compared in the hydrogenation of 2,4-dinitrotoluene (DNT). Both catalysts have shown high activity in the hydrogenation tests. The DNT conversion exceeded $98 \%$ in both cases, whereas the 2,4-toluenediamine (TDA) yields were $99.7 \mathrm{n} / \mathrm{n} \%$ and $98.8 \mathrm{n} / \mathrm{n} \%$, with the $\mathrm{Pd} / \mathrm{CrO}_{2}$ and $\mathrm{Pt} / \mathrm{CrO}_{2}$, respectively, at $333 \mathrm{~K}$ and 20 bar $\mathrm{H}_{2}$ pressure. In the case of the $\mathrm{Pt} / \mathrm{CrO}_{2}$ catalyst, $304.08 \mathrm{~mol}$ of TDA formed with $1 \mathrm{~mol} \mathrm{Pt}$ after $1 \mathrm{~h}$ hydrogenation. Activation energies were also calculated to be approximately $24 \mathrm{~kJ} \cdot \mathrm{mol}^{-1}$. Besides their immediate applicability, our catalysts were well dispersible in the reaction medium (methanolic solution of DNT). Moreover, because of their magnetic behavior, the catalysts were easy to handle and remove from the reaction media by using a magnetic field.
\end{abstract}

Keywords: nanowire; magnetic catalyst; hydrogenation; 2,4-toluenediamine; activation energy

\section{Introduction}

Polyurethanes (PUs) are one of the most versatile class of polymers with specific mechanical, physical, biological, and chemical properties giving them great potential for use in different applications, such as flexible and rigid foams, adhesives, paints, coatings, and elastomers. There is an ever-growing demand for toluene diisocyanate (TDI), which is one of the isocyanate components for making PUs; by 2018, global TDI production capacity reached 3.355 million tons per year. The main commercial route for the manufacture of TDI starts with the nitration of toluene using nitric acid to produce dinitrotoluene followed by catalytic hydrogenation to toluene diamine.

2,4-toluenediamine (2,4-TDA) is an important intermediate in the production of toluene diisocyanate (TDI). 2,4-TDA is produced industrially by the catalytic hydrogenation of 2,4-dinitrotoluene (2,4-DNT) in the liquid phase. Numerous catalysts have been 
developed to produce TDA to achieve the highest possible yield and selectivity in the reaction. The most important catalysts are Raney nickel, carbon-supported palladium or platinum [1-6], and silica- $[7,8]$ or alumina-supported $[9,10]$ transition metals.

The rate and selectivity of hydrogenation of aromatic nitro compounds depends on the pressure, temperature, catalyst type, and concentration. As the hydrogen pressure increases, the hydrogenation rate of the nitro compounds also increases [6]. Previous studies on palladium catalysts have concluded that the degree of activity and selectivity depends on the particle size of the palladium. Examination of larger Pd particles has shown that both the specific activity and the selectivity of the 2,4-nitrohydroxiaminotoluene (2,4HANT) isomers are increased [4]. Industrial applications require a good balance between a catalyst's performance and its recoverability. Catalyst pellets are easy to recover from the reaction medium; however, the contact surface is smaller between the reagent molecules and the catalyst's reducing performance. Nanoparticle-based supports offer a high specific surface and good dispersibility; however, as most of the catalysts are powder-based, their separation from the reaction medium is very difficult by conventional methods, such as filtration or centrifugation, after the reaction completed.

This issue can be eliminated by the use of magnetic supports, which is a novel approach in the development of heterogeneous catalytic systems [11-15]. The magnetic support allows easy and efficient separation from the reaction mixture by means of an external magnetic field, thus facilitating the recovery and recyclability [16] of the catalyst. Furthermore, the catalytic activity of the magnetically separable nanoparticles is good because of their large surface area, high stability, and good dispersion in the reaction mixture.

Chromium dioxide $\left(\mathrm{CrO}_{2}\right)$, also known as Magtrieve ${ }^{\mathrm{TM}}$, is an extremely interesting metal oxide that can be easily removed from the reaction medium because of its heterogeneous nature and ferromagnetic properties [17]. $\mathrm{CrO}_{2}$ films and nanostructures are also important in spintronic applications [18-21]. Because of its exceptional properties as a magnetic storage medium, it is widely used in audio, video, and computer technology [22]. Furthermore, Magtrieve ${ }^{\mathrm{TM}}$ is a magnetically recoverable oxidizing agent also used in organic synthesis [23-25], such as for the selective oxidation of alcohols in the form of the corresponding aldehydes, ketones, or carboxylic acids $[17,26,27]$.

Conventional catalyst preparation processes usually consist of several steps including post-treatment to activate the catalysts, which can be avoided by using a sonochemical method $[28,29]$. By applying sonochemical treatment, an active catalyst can be achieved in only one step [28,29]. The intense ultrasonic irradiation- (sonication) induced sound waves initiate cycles of high and low pressure in the liquid medium. The vapor pressure of the solvent decreases momentarily, which results in the formation of bubbles of a few micrometers in the mixture. These bubbles are pulsating and growing until they reach a higher pressure range in the liquid, where they will collapse as the pressure increases [30]. These are the so-called "hot spots", where a huge amount of energy is released, causing the liquid phase (i.e., alcohols) to act as a reducing agent in the reaction and initiate the nucleation processes of metal or metal oxide nanoparticles [31-34]. Here, we report the preparation and investigation of a highly effective and selective magnetic catalyst for DNT hydrogenation. In the present work, palladium and platinum nanoparticles were deposited onto the surface of chromium dioxide in ethanol by using a sonochemical treatment. The activity of the catalysts was tested in 2,4-DNT hydrogenation. Because of the magnetic properties of the catalytic systems, these can be easily and efficiently separated from the reaction mixture by magnetic separation at the end of the hydrogenation process.

\section{Results and Discussion}

\subsection{Preparation and Characterization of the Pd-and Pt-Decorated Chromium(IV)} Oxide Nanowires

The preparation of the palladium-decorated magnetic nanowires is highlighted in Figure 1. The detailed procedure for both $\mathrm{Pd}$ and $\mathrm{Pt}$ is found in the experimental section. 


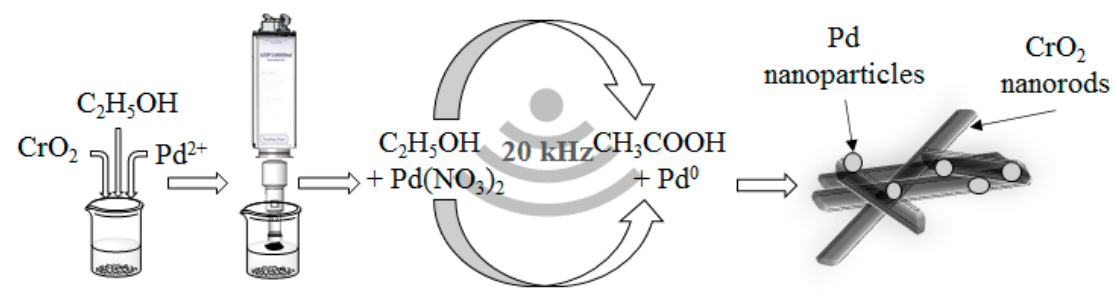

Figure 1. Preparation steps of the $\mathrm{Pd} / \mathrm{CrO}_{2}$ magnetic catalyst by using a sonochemical treatment.

The specific surface area is a key factor related to catalyst performance. Therefore, the specific surface area of the catalysts was determined based on the Brauner-EmmettTeller (BET) method. There was no significant difference between the $\mathrm{Pd} / \mathrm{CrO}_{2}$ and $\mathrm{Pt} / \mathrm{CrO}_{2}$ as their corresponding values were found to be $31.54 \mathrm{~m}^{2} \mathrm{~g}^{-1}$ and $30.08 \mathrm{~m}^{2} \mathrm{~g}^{-1}$, respectively. High-resolution transmission electron microscopy (HRTEM) was also applied in the characterization of the catalysts. The fibrous structure of the chromium dioxide nanowires can be seen on the TEM images, and it was found that their diameter varied between 6 and $60 \mathrm{~nm}$, while their length was between 60 and $870 \mathrm{~nm}$ (Figure 2A-D). In the $\mathrm{Pd} / \mathrm{CrO}_{2}$ system, the palladium nanoparticles were also located on the surface of the $\mathrm{CrO}_{2}$ nanowires, and the corresponding particle size was quite small, 6-20 nm (Figure 2B). In contrast, in the case of the platinum-decorated sample, the particles formed larger $(70-80 \mathrm{~nm})$ aggregates (Figure 2D).

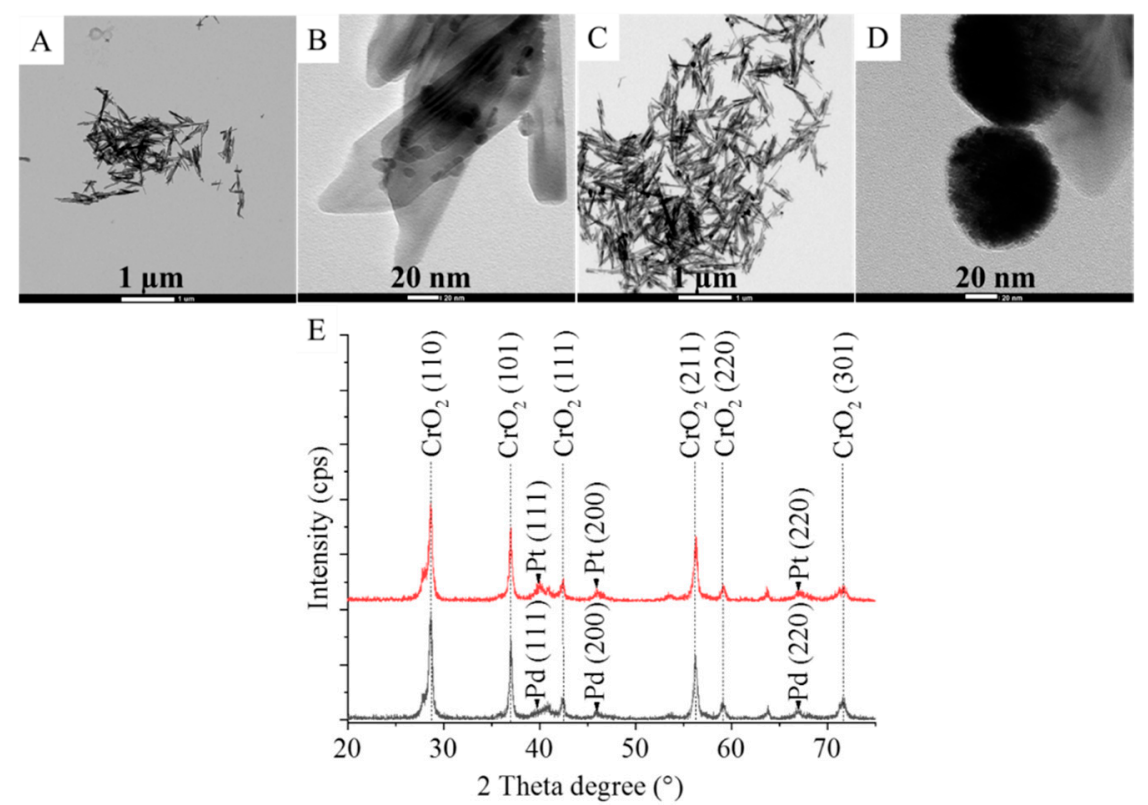

Figure 2. TEM images of $(\mathbf{A}, \mathbf{B})$ the $\mathrm{Pd} / \mathrm{CrO}_{2}$ and $(\mathbf{C}, \mathbf{D})$ the $\mathrm{Pt} / \mathrm{CrO}_{2}$ catalysts, and (E) the corresponding XRD patterns.

On closer inspection, it can be observed that the 70-80 nm spherical Pt aggregates build up from several very small (only several nanometers) particles (Figure S1 in the Supplementary Materials). The smaller platinum particles have a significantly larger specific surface with more catalytically active Pt atoms on the surface than in the case of palladium aggregates. These surface atoms are accessible to the reactant molecules (DNT and $\mathrm{H}_{2}$ ), which results in a more efficient transformation, as is described later. Deposition of the two precious metals was different, since the reduction of palladium(II)-ions from the corresponding nitrate salt by ethanol proceeded easily. However, the reduction of $\mathrm{Pt}(\mathrm{IV})$ ions from their stable complex $\left(\mathrm{H}_{2} \mathrm{PtCl}_{6}\right)$ failed with methanol. Thus, the deposition of platinum particles was realized using another stronger reducing agent, namely, hydrazine solution. The different reduction methods may have resulted in different nucleation and 
crystallization rates, which could influence the particle size. Consequently, the different reduction methods may explain the aggregate formation of the platinum nanoparticles.

The presence of the elemental palladium was confirmed by XRD measurements. On the diffractogram of the $\mathrm{Pd} / \mathrm{CrO}_{2}$ catalyst, reflections at $40.2^{\circ}(111), 46.1^{\circ}(200)$, and $66.9^{\circ}$ (220) $2 \theta$ degrees (JCPDS card number 046-1043) could be seen, which can be associated with the presence of elemental palladium (Figure 2E). The platinum catalyst was also identified and characterized, and reflection peaks were found at $39.8^{\circ}(111), 45.9^{\circ}(200)$, and $67.0^{\circ}$ (220) (two theta degrees) (JCPDS card 04-0802), which indicates the presence of elemental platinum (Figure 2E). Thus, the reduction of the $\mathrm{Pd}(\mathrm{II})$ and $\mathrm{Pt}(\mathrm{IV})$ ions was successful. Additional peaks were also visible on the diffractograms at $28.7^{\circ}, 36.9^{\circ}, 42.4^{\circ}$, $56.2^{\circ}, 59.1^{\circ}$, and $71.7^{\circ}$ (two theta degrees), which were identified as the reflections of the (110), (101), (111), (211), (220), and (301) crystalline phases of the catalyst support, magnetic chromium dioxide (JCPDS card number 84-1819).

\subsection{Comparison of the Catalytic Activity of the Synthesized Pd and Pt Decorated Chromium(IV)} Oxide Nanowires

The catalytic activity of the magnetic Pd-and Pt-containing catalysts was tested in DNT hydrogenation at four different reaction temperatures, and the actual DNT concentration was continuously monitored. The precious metal-free $\mathrm{CrO}_{2}$ support was also tested at $333 \mathrm{~K}$ and 20 bar pressure. In the case of the palladium- and platinum-free $\mathrm{CrO}_{2}$, a $53.9 \mathrm{n} / \mathrm{n} \%$ DNT conversion and a $20.1 \mathrm{n} / \mathrm{n} \%$ TDA yield were reached after $240 \mathrm{~min}$. The low DNT conversion and TDA yield indicate that Pd or Pt is necessary to achieve a catalytic system of high-performance.

By applying the $\mathrm{Pd} / \mathrm{CrO}_{2}$ or $\mathrm{Pt} / \mathrm{CrO}_{2}$ catalyst, the hydrogenation reaction under investigation happens according to a pseudo-first-order kinetics, which was verified by linear regression on the initial experimental points of the $\ln \left(\mathrm{c}_{\mathrm{DNT}}\right)$ vs. reaction time plot (Figure 3).

A
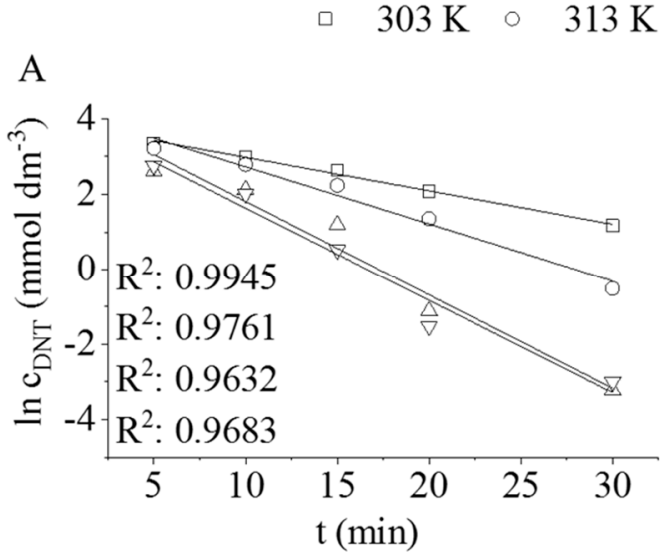

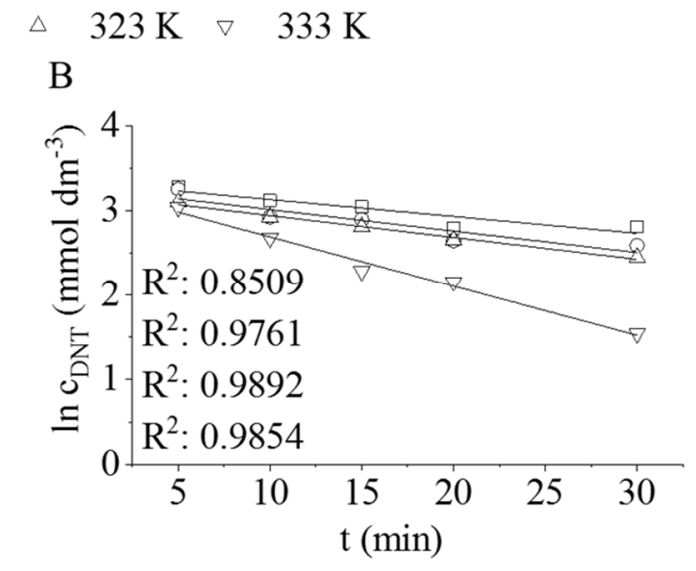

Figure 3. $\ln \left(\mathrm{c}_{\mathrm{DNT}}\right)$ vs. reaction time diagrams of DNT hydrogenation by applying (A) the $\mathrm{Pt} / \mathrm{CrO}_{2}$ or (B) the $\mathrm{Pd} / \mathrm{CrO}_{2}$ catalyst.

High DNT conversions were achieved with both catalysts. The platinum-containing sample reacted faster, which can be seen by comparing the steep run of the conversion curves (Figure $4 \mathrm{~A}, \mathrm{~B}$ ). The system reached full conversion with the $\mathrm{Pt} / \mathrm{CrO}_{2}$ catalyst after $40 \mathrm{~min}$ at $323 \mathrm{~K}$ and 20 bar hydrogen pressure. The $\mathrm{Pd} / \mathrm{CrO}_{2}$ sample was slightly less active than its counterpart, but, after $80 \mathrm{~min}$ of hydrogenation at $333 \mathrm{~K}$ and $20 \mathrm{bar}$, it was also able to reach full DNT conversion (Figure 4B). 

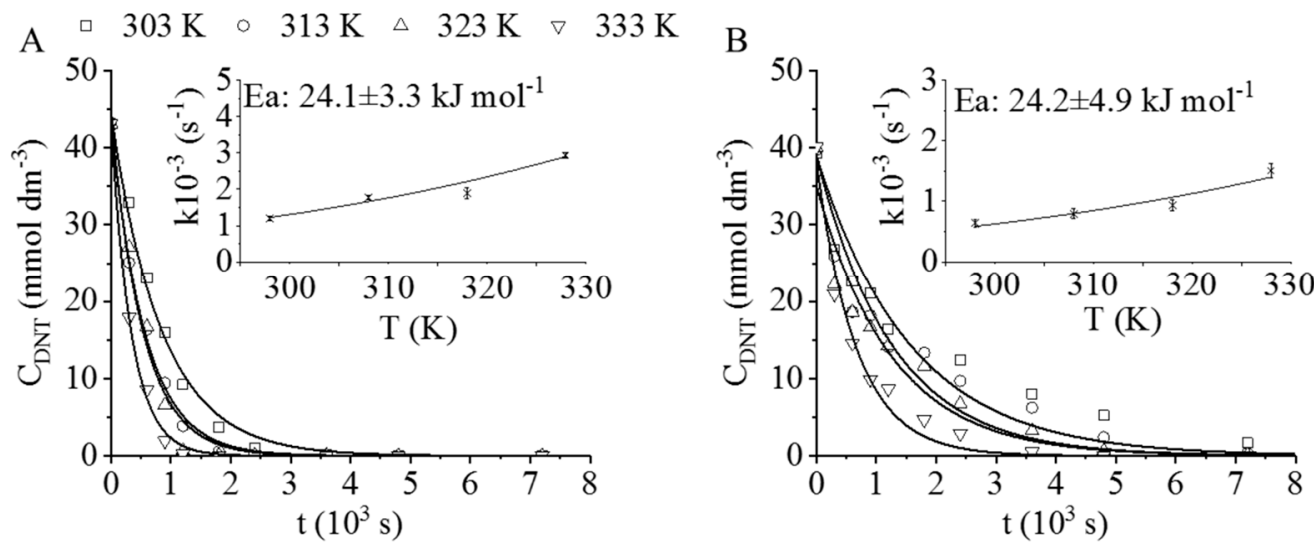

Figure 4. Dinitrotoluene $(\mathrm{DNT})$ conversion $\left(\mathrm{mmol} \mathrm{dm}^{-3}\right)$ vs. reaction time measured at four temperatures (303-333 K) and the corresponding Arrhenius plots in the case of $(\mathbf{A})$ the $\mathrm{Pt} / \mathrm{CrO}_{2}$ and (B) the $\mathrm{Pd} / \mathrm{CrO}_{2}$ catalysts.

A non-linear regression method was applied to calculate the reaction rate constants $(k)$ (see Equation (3) in the experimental section and Table 1) [35]. In the case of the $\mathrm{Pt} / \mathrm{CrO}_{2}$, the $k$ values were higher (e.g., $2.9 \times 10^{-3} \mathrm{~s}^{-1}$ at $333 \mathrm{~K}$ ) compared to the Pd-containing catalyst (e.g., $1.5 \times 10^{-3} \mathrm{~s}^{-1}$ at $333 \mathrm{~K}$ ) despite the lower quantity of the precious metal $\left(1.55 \times 10^{-4} \mathrm{~mol} \mathrm{Pt}\right.$ in $1 \mathrm{~g}$ catalyst and $4.25 \times 10^{-4} \mathrm{~mol} \mathrm{Pd}$ in $1 \mathrm{~g}$ catalyst, respectively).

Table 1. 2,4-Dinitrotoluene hydrogenation reaction rate constants $(k)$ calculated at four different temperatures and the corresponding activation energy $\left(\mathrm{E}_{\mathrm{a}}\right)$ values achieved by applying the $\mathrm{Pt} / \mathrm{CrO}$ and $\mathrm{Pd} / \mathrm{CrO}_{2}$ catalysts.

\begin{tabular}{|c|c|c|c|c|c|}
\hline & \multicolumn{4}{|c|}{$k\left(s^{-1}\right)$} & \multirow{2}{*}{$\begin{array}{c}\text { Ea } \\
(\mathrm{kJ} / \mathrm{mol})\end{array}$} \\
\hline & $303 \mathrm{~K}$ & $313 \mathrm{~K}$ & $323 \mathrm{~K}$ & $333 \mathrm{~K}$ & \\
\hline $\begin{array}{l}\mathrm{Pt} / \mathrm{CrO}_{2} \\
\mathrm{Pd} / \mathrm{CrO}_{2}\end{array}$ & $\begin{array}{l}1.2 \times 10^{-3} \pm 5.5 \times 10^{-5} \\
6.4 \times 10^{-4} \pm 7.1 \times 10^{-5}\end{array}$ & $\begin{array}{l}1.8 \times 10^{-3} \pm 5.6 \times 10^{-5} \\
7.9 \times 10^{-4} \pm 8.1 \times 10^{-5}\end{array}$ & $\begin{array}{l}1.9 \times 10^{-3} \pm 1.4 \times 10^{-4} \\
9.3 \times 10^{-4} \pm 9.4 \times 10^{-5}\end{array}$ & $\begin{array}{l}2.9 \times 10^{-3} \pm 8.6 \times 10^{-5} \\
1.5 \times 10^{-3} \pm 1.2 \times 10^{-4}\end{array}$ & $\begin{array}{l}24.1 \pm 3.3 \\
24.2 \pm 4.9\end{array}$ \\
\hline
\end{tabular}

The activation energies (Ea) were also calculated based on the Arrhenius plot by applying the rate constant $(\mathrm{k})$ vs. temperature $(\mathrm{T})$ diagrams (Figure 4). The fitting was carried out using the original exponential Arrhenius expression (Equation (5)) to avoid the biased error propagation of the parameters (Figure S2A,B). There was no significant difference between the Ea values of the reactions carried out with the tested catalysts (Table 1). However, these activation energies were lower compared to other experimental results in the literature $(32.3 \pm 7.5$ and $38.6 \pm 3.3 \mathrm{~kJ} / \mathrm{mol})[36,37]$.

The quantity of the adsorbed precious metals was significantly different in the case of the two catalysts. Thus, the catalytic activity of the two magnetic catalysts was compared by using the corresponding turnover numbers (TON) (Equation (4) in the experimental section), which were calculated after $1 \mathrm{~h}$ of hydrogenation. In both cases, the TON increased by increasing the temperature, and thus, the highest values were achieved at $333 \mathrm{~K}$. In the case of the $\mathrm{Pt} / \mathrm{CrO}_{2}$ catalyst, $304.08 \mathrm{~mol}$ of TDA formed within $60 \mathrm{~min}$ at $333 \mathrm{~K}$ and 20 bar pressure (Table 2). The palladium-containing catalyst was less active under the same reaction conditions because only $60.14 \mathrm{~mol}$ of TDA formed considering $1 \mathrm{~mol}$ of $\mathrm{Pd}$.

Table 2. Turnover numbers (TON) (Equation (4)) after $1 \mathrm{~h}$ hydrogenation by using of the $\mathrm{Pt} / \mathrm{CrO}_{2}$ and $\mathrm{Pd} / \mathrm{CrO}_{2}$ magnetic catalysts at $303,313,323$, and $333 \mathrm{~K}$.

\begin{tabular}{ccccc}
\hline & \multicolumn{4}{c}{ TON $\left[\mathbf{m o l}_{\mathbf{T D A}} / \mathbf{m o l}_{\mathbf{P d} / \mathbf{P t}}\right]$} \\
\cline { 2 - 5 } & $\mathbf{3 0 3} \mathbf{K}$ & $\mathbf{3 1 3 ~ K}$ & $\mathbf{3 2 3} \mathbf{K}$ & $\mathbf{3 3 3 ~ \mathbf { K }}$ \\
\hline $\mathbf{P t} / \mathrm{CrO}_{2}$ & 18.90 & 85.37 & 87.89 & 304.08 \\
$\mathbf{P d} / \mathrm{CrO}_{\mathbf{2}}$ & 12.71 & 17.27 & 43.69 & 60.14 \\
\hline
\end{tabular}


The formation of semi-hydrogenated intermediates, 4-amino-2-nitrotoluene (4A2NT) and 2-amino-4-nitrotoluene (2A4NT), were confirmed during the hydrogenation (Figure 5). In the case of the $\mathrm{Pt} / \mathrm{CrO}_{2}$, the total amount of the intermediates was converted to TDA at higher temperatures $(323 \mathrm{~K}$ and $333 \mathrm{~K})$. However, the semi-hydrogenated compounds have been detected even after four hours of catalytic hydrogenation with $\mathrm{Pd} / \mathrm{CrO}_{2}$.
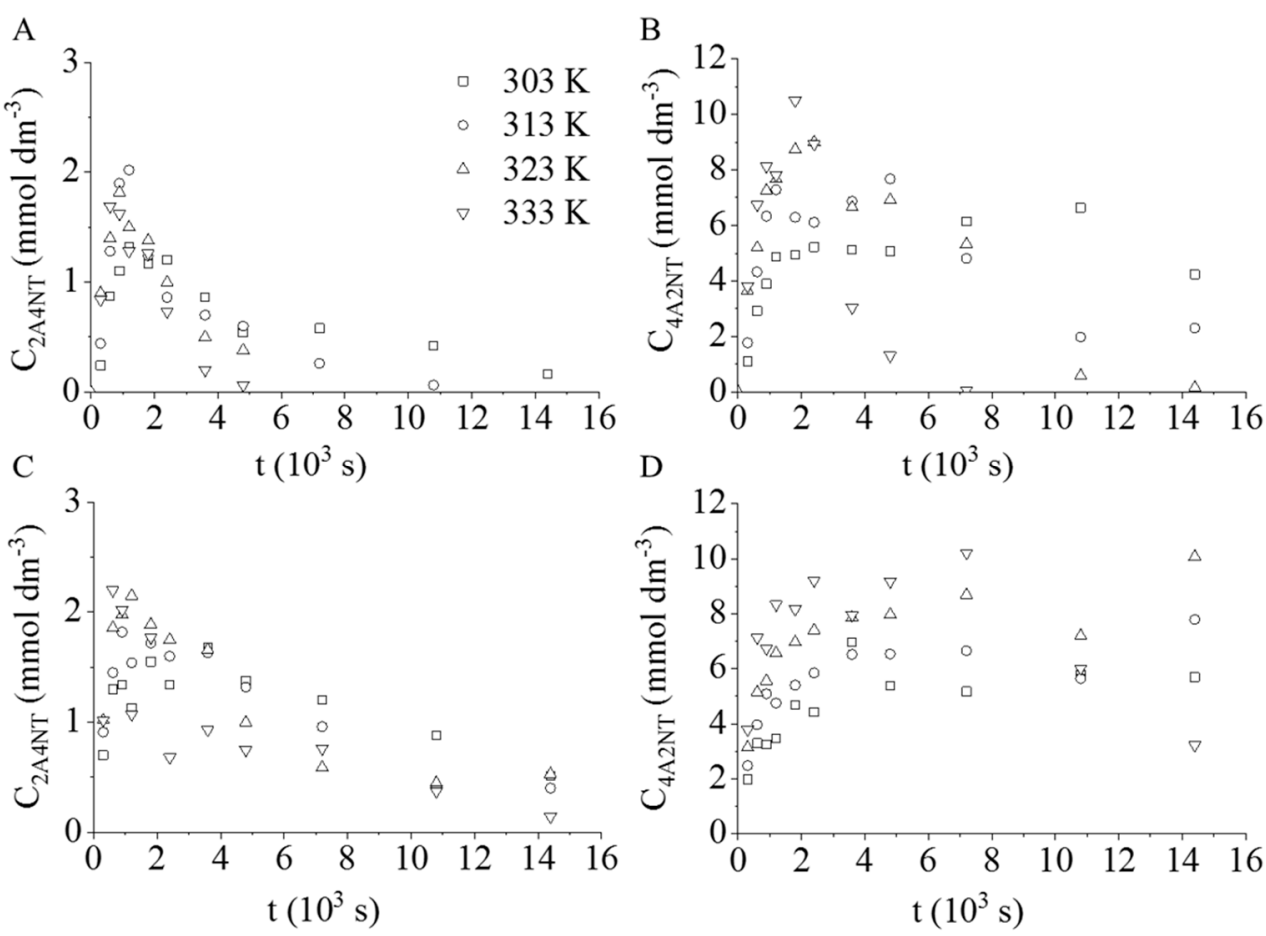

Figure 5. Concentration vs. hydrogenation time of 2-amino-4-nitrotoluene (2A4NT) and 4-amino-2nitrotoluene (4A2NT) measured in the presence of $(\mathbf{A}, \mathbf{B}) \mathrm{Pt} / \mathrm{CrO}_{2}$ and $(\mathbf{C}, \mathbf{D}) \mathrm{Pd} / \mathrm{CrO}_{2}$, respectively.

\subsection{Possible Mechanism for the Hydrogenation}

The formation of TDA (Figure 6, middle section) took place through six consecutive hydrogenation steps. In the first step, nitroso-nitrotoluene is formed, which is followed by a hydroxylamine-nitrotoluene formation. This leads to the formation of one of the abovementioned semi-hydrogenated compounds; depending on which nitro group is hydrogenated first, $2 \mathrm{~A} 4 \mathrm{NT}$ or $4 \mathrm{~A} 2 \mathrm{NT}$ will be formed. After the other nitro group is hydrogenated, the corresponding nitroso and hydroxylamine compounds will be produced. In the last step, both pathways will lead to the main product, TDA. These results are completely in line with the findings of Giovanni et al. [1], who also detected the presence of nitroso and hydroxylamine compounds during the hydrogenation of DNT over a $\operatorname{Pd}(C)$ catalyst. In their case, the two abovementioned compounds further reacted to give $2,2^{\prime}$-dinitro- $4,4^{\prime}$ azoxytoluene (DNAT). Our reaction mixture was subjected to Gas Chromatography-Mass Spectrometry (GC-MS) investigation to detect and identify any intermediate present. The possible structures were identified from the MS spectra using the NIST 08, NIST Mass Spectral Library. Much to our surprise, no DNAT or diazo compounds from the reaction of the corresponding amines and nitroxyl-compounds were detected, maybe because of their low stability under GC-MS conditions. Instead, several side-products were identified (Figure 6, see 2-4) in trace amounts in addition to the two semi-hydrogenated intermediates (4A2NT and 2A4NT) during the reaction. The corresponding GC-MS spectra are presented in the Supplementary Materials as Figures S3-S5. In addition to the detected side-products, we assumed the formation of several other ones (1 and 5-7 in Figure 6). The reaction pathways were highlighted to explain the formation of these species. Nota condensation reaction, (E)-1-(2,4-dinitrophenyl)- $N$-(2-methyl-5-nitrophenyl)methanimine may form from 2,4-DNT by the loss of water (Figure 6, see 1). Another condensed molecule, 
2-[(E)-[(2-methyl-5-nitrophenyl)imino]methyl]-5-nitrophenol was identified, which could be formed through side-reactions by water loss (Figure 6, see 2). Reaction between the 4-methylbenzene-1,3-diol and the 2-nitroso-4-nitrotoluene led to the formation of 4-[(E)-[(2methyl-5-nitrophenyl)imino]methyl]benzene-1,3-diol (Figure 6, see 3).
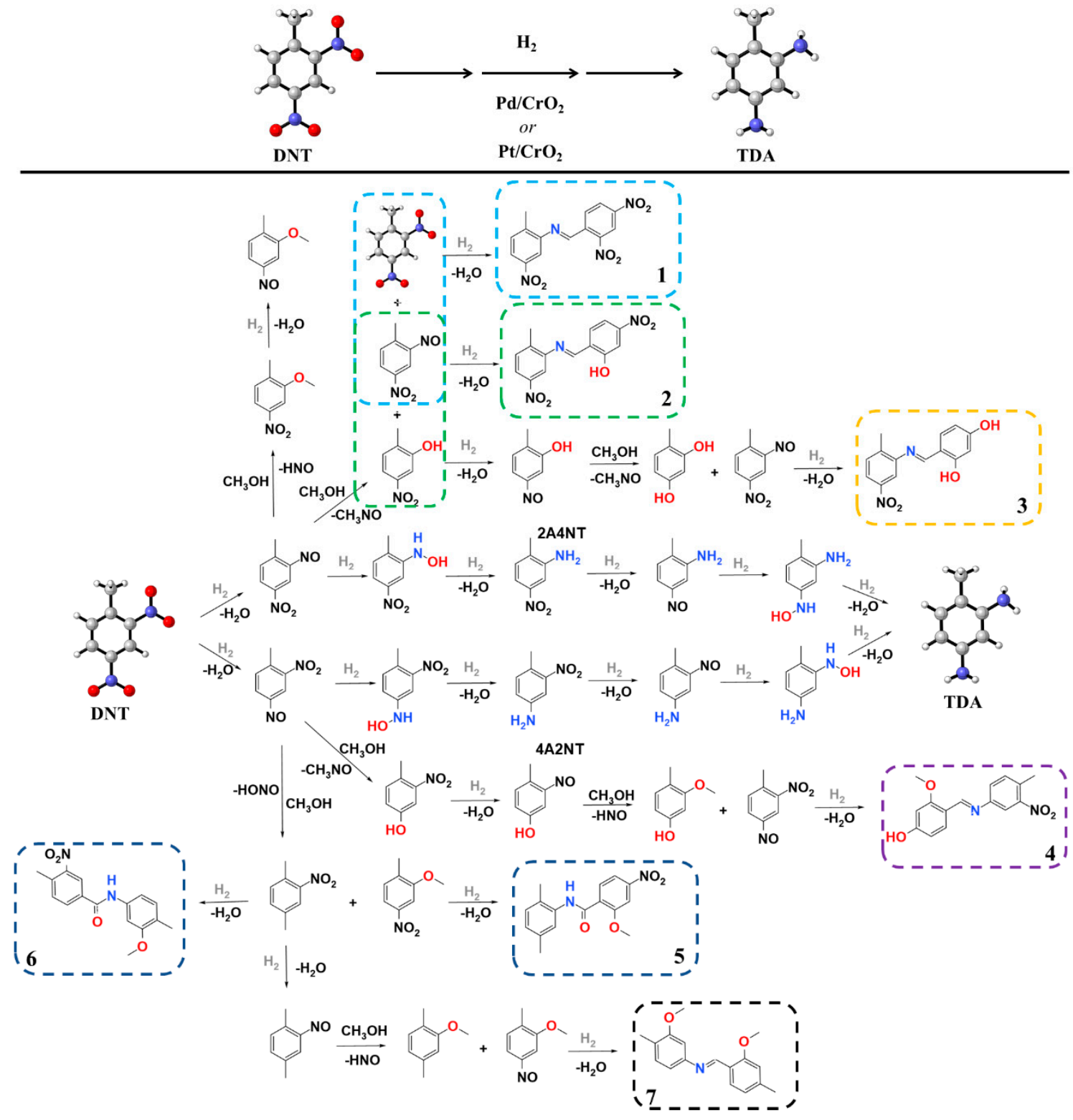

Figure 6. Proposed mechanism of 2,4-dinitrotoluene hydrogenation to produce 2,4-toluenediamine (TDA) with $\mathrm{Pd} / \mathrm{CrO}_{2}$ or $\mathrm{Pt} / \mathrm{CrO}_{2}$ catalysts. The reaction pathways depict the formation of specific side-products (dashed frames) detected or assumed during the measurements.

The 2-nitro-4-nitrosotoluene can react with 2-methoxy-4-methylphenol and reach 3methoxy-4-[(E)-[(4-methyl-3-nitrophenyl)imino]methyl]phenol (Figure 6, see 4). The formation of two stereoisomers, $\mathrm{N}$-(2,5-dimethylphenyl)-2-methoxy-4-nitrobenzamide and $\mathrm{N}$-(3methoxy-4-methylphenyl)-4-methyl-3-nitrobenzamide, could occur by the reaction of 1,4dimethyl-2-nitrobenzene and 2-methoxy-1-methyl-4-nitrobenzene (Figure 6, see 5 and 6). Moreover, the (E)-1-(2-methoxy-4-methylphenyl)- $N$-(3-methoxy-4-methylphenyl)methanimine side-product could form through multiple steps (Figure 6, see 7). 
As it is evident from Figure 6, compounds 1-4 and 7 contain imine bonds that can be formed via the reaction of the aromatic amines and the methyl group of the other toluene derivative. This reaction may seem very unlikely at first glance; however, Brandt et al. recently reported the direct alkylation of aliphatic amines via the activation of the $\mathrm{sp}^{3} \mathrm{C}-\mathrm{H}$ bond of pure hydrocarbons, e.g., toluene using an amide-based nickel pincer catalyst [38]. The $\mathrm{C}-\mathrm{H}$ bonds are very stable by nature, however, alkylation of nitrobenzene with toluene moieties has been reported using a heterogeneous cobalt catalyst in the presence of peroxide and hydrogen. [39] These findings indicate that, by altering the reaction conditions, our catalysts may be also used for the preparation of imines and/or amines by the direct reaction of $\mathrm{C}-\mathrm{H}$ bonds and amines.

\subsection{Turnover Number and Reusability}

TDA yields were similar in the case of both catalysts, $98.8 \mathrm{n} / \mathrm{n} \%\left(\mathrm{Pt} / \mathrm{CrO}_{2}\right)$ and $99.7 \mathrm{n} / \mathrm{n} \%\left(\mathrm{Pd} / \mathrm{CrO}_{2}\right)$ at $333 \mathrm{~K}$ and 20 bar hydrogen pressure despite the fact that the quantities of the precious metals in the catalysts were different (Pt: $3.02 \mathrm{wt} \%$, Pd: $4.52 \mathrm{wt} \%$ ). At lower temperatures ( $303 \mathrm{~K}$ and $313 \mathrm{~K}$ ), higher TDA yields $(57.0 \mathrm{n} / \mathrm{n} \%$ and $76.1 \mathrm{n} / \mathrm{n} \%$ ) were achieved by using the $\mathrm{Pt} / \mathrm{CrO}_{2}$ catalyst, despite its lower metal content. The catalysts were well dispersible in methanolic solution (Figure 7B). Furthermore, because of the magnetic properties of the $\mathrm{CrO}_{2}$ support, the separation of the catalysts from the reaction media was easy, efficient, and fast by using a magnetic field (Figure $7 \mathrm{C}$ ). The $\mathrm{Pd} / \mathrm{CrO}_{2}$ and $\mathrm{Pt} / \mathrm{CrO}_{2}$ particles formed stable dispersions with the reaction media in a methanolic solution of DNT and TDA (Figure 7B). The stable catalyst dispersions could be separated using an external magnetic field since the magnetic catalyst particles were collectable by a neodymium magnet from the methanolic phase; therefore, the liquid became clear (Figure 7C).

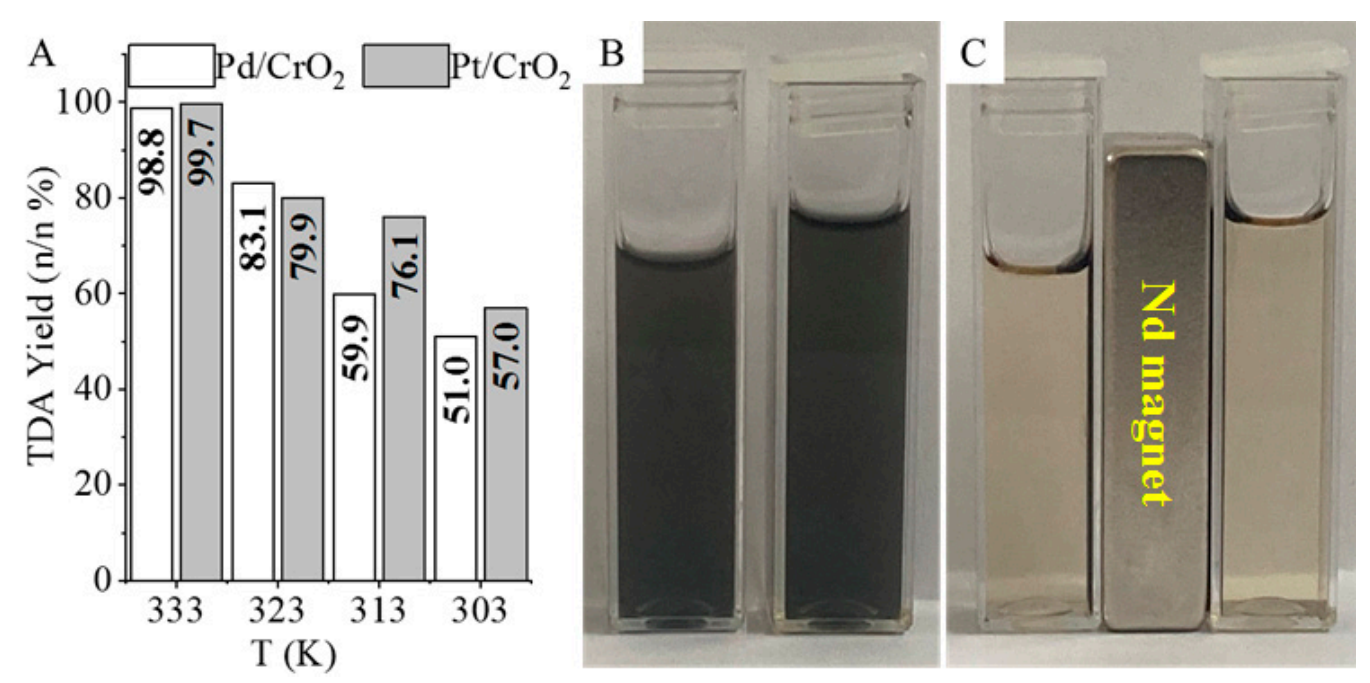

Figure 7. (A) TDA yields of the magnetic $\mathrm{Pt} / \mathrm{CrO}_{2}$ and $\mathrm{Pd} / \mathrm{CrO}_{2}$ catalysts at different temperatures; (B) demonstration of the stable dispersions of the catalysts; and $(\mathbf{C})$ their efficient magnetic separation by using a neodymium magnet.

Four reusability tests of the catalysts were also carried out without regeneration. Before each reuse test, the catalysts were washed with methanol, and dried at $105{ }^{\circ} \mathrm{C}$ overnight; in this sense, the methanolic rinsing was a sufficient post-treatment of the catalysts before the next use. The DNT conversion did not decrease after four cycles, and the maximum conversions were above $99 \mathrm{n} / \mathrm{n} \%$ in the case of the $\mathrm{Pt} / \mathrm{CrO}_{2}$ catalyst (Figure 8A). 
A

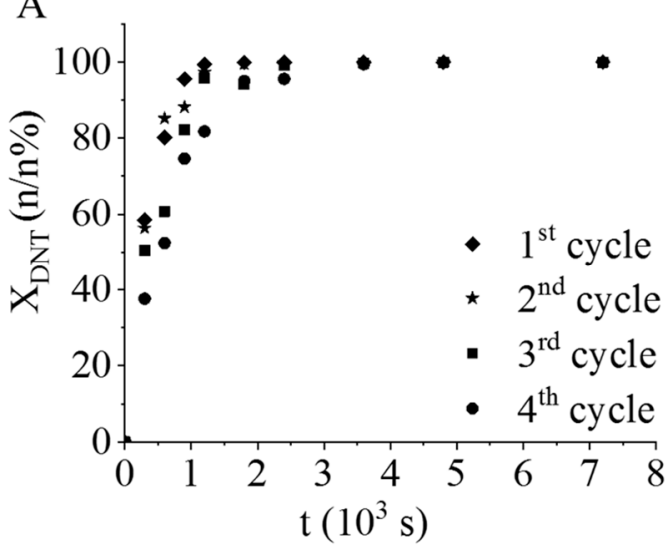

B

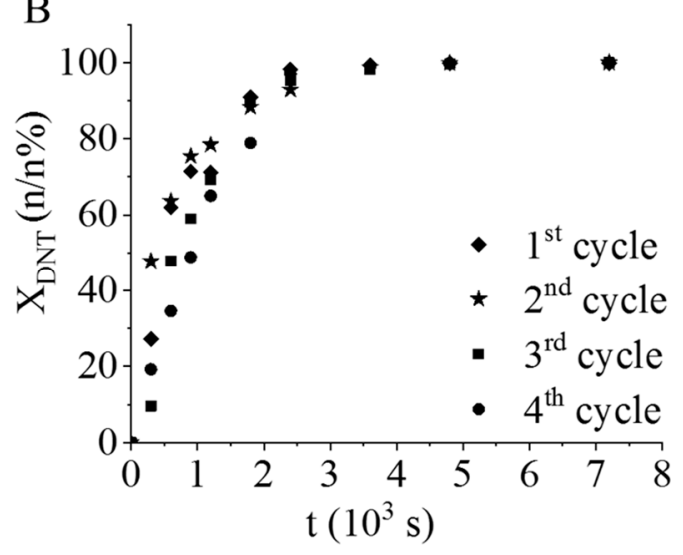

Figure 8. Reuse tests of the catalysts. DNT conversion vs. time by applying (A) the $\mathrm{Pt} / \mathrm{CrO}_{2}$ and $(\mathbf{B})$ the $\mathrm{Pd} / \mathrm{CrO}$ samples.

However, after each cycle, a slight decrease in the slope was seen on the conversion curves, which indicate a small decrease in the reaction rate. A similar tendency was experienced in the case of the $\mathrm{Pd} / \mathrm{CrO}_{2}$ catalyst, and the DNT conversion was also above $99 \mathrm{n} / \mathrm{n} \%$ after $60 \mathrm{~min}$. In summary, the catalysts remained active after four cycles without regeneration.

\section{Materials and Methods}

\subsection{Materials}

Palladium(II) nitrate dihydrate $\left(\mathrm{Pd}\left(\mathrm{NO}_{3}\right)_{2} \cdot 2 \mathrm{H}_{2} \mathrm{O}\right.$, Merck Ltd., Darmstadt, Germany) and dihydrogen hexachloroplatinate(IV) hydrate $\left(\mathrm{H}_{2} \mathrm{PtCl}_{6} \cdot \mathrm{H}_{2} \mathrm{O}\right.$, Alfa Aesar Ltd., Ward Hill, MA, USA) were used as precursors during the catalyst preparation. Patosolv (96-98\% ethanol, 2-4\% i-propanol, Molar Chem. Ltd., Budapest, Hungary) and water were used as solvents; hydrazine hydrate was applied as a reducing agent, while Magtrieve ${ }^{\mathrm{TM}}$ chromium(IV) oxide $\left(\mathrm{CrO}_{2}\right.$, Sigma Aldrich Ltd., St. Louis, $\mathrm{MO}$, USA) was used as magnetic catalyst support.

\subsection{The Preparation of $\mathrm{Pd} / \mathrm{CrO}_{2}$ and $\mathrm{Pt} / \mathrm{CrO}_{2}$ Catalysts}

Palladium nitrate dihydrate $(0.25 \mathrm{~g})$ was dissolved in $50 \mathrm{~mL}$ of patosolv and $2.00 \mathrm{~g}$ Magtrieve ${ }^{\mathrm{TM}}$ was added to the solution (Figure 1). The $\mathrm{CrO}_{2}$ was dispersed by using a Hielscher UIP1000hDT Ultrasound Homogenizer for 2 min (115 W, $19.43 \mathrm{kHz})$. Pd(IV) ions were reduced to elemental $\mathrm{Pd}$ nanoparticles. After the reduction, the prepared magnetic $\mathrm{Pd} / \mathrm{CrO}_{2}$ catalyst was separated from the liquid phase by using a neodymium magnet, and it was washed by patosolv. The magnetic sample was dried at $105^{\circ} \mathrm{C}$ overnight.

During the $\mathrm{Pt} / \mathrm{CrO}_{2}$ catalyst preparation, $0.21 \mathrm{~g}$ of dihydrogen hexachloroplatinate(IV) dihydrate was dissolved in $50 \mathrm{~mL}$ distilled water, and $2.00 \mathrm{~g} \mathrm{Magtriev}^{\mathrm{TM}}$ was dispersed in the solution by using the homogenizer. Hydrazine hydrate $(1 \mathrm{~mL})$ was applied as a reducing agent. The palladium and platinum nanoparticles were deposited onto the chromium(IV) oxide nanowires by adsorption, and the real Pd an Pt contents were checked by Inductively coupled plasma - optical emission spectrometry (ICP-OES) elemental analysis. The precious metal contents of the $\mathrm{Pd} / \mathrm{CrO}_{2}$ and $\mathrm{Pt} / \mathrm{CrO}_{2}$ catalyst were $4.52 \mathrm{wt} \%\left(4.25 \times 10^{-4} \mathrm{~mol} \mathrm{Pd}\right.$ in $1 \mathrm{~g}$ catalyst $)$ and $3.02 \mathrm{wt} \%\left(1.55 \times 10^{-4} \mathrm{~mol} \mathrm{Pt}\right.$ in $1 \mathrm{~g}$ catalyst $)$, respectively.

\subsection{Characterization Technics}

The morphology and particle size of the palladium- and platinum-decorated $\mathrm{CrO}_{2}$ nanowires were examined by high-resolution transmission electron microscopy (HRTEM, FEI Technai G2 electron microscope, $200 \mathrm{kV}$ ). Aqueous suspensions of the samples were dosed onto the surface of copper grids (Ted Pella Inc., only carbon, 300 mesh). The particle size of the nanoparticles was measured on the HRTEM images based on the original scale bar by using the ImageJ software. X-ray diffraction (XRD) measurements were 
applied to identify the metal phases in the catalytic systems by using a Rigaku Miniflex II diffractometer with a $\mathrm{Cu} \mathrm{K} \alpha$ radiation source $(30 \mathrm{kV}, 15 \mathrm{~mA})$. Specific surface area measurements were also carried out by using a nitrogen adsorption-desorption method at $77 \mathrm{~K}$ with a Micromeritics ASAP 2020 sorptometer based on the Brauner-Emmett-Teller (BET) method. The quantities of platinum and palladium in the catalysts were measured by using a Varian 720-ES inductively coupled plasma-optical emission spectrometer (ICP-OES). The analysis was carried out by using the Merck Certipur ICP multi-element IV standard. The samples were solved in aqua regia (mixture of nitric acid and hydrochloric acid in a molar ratio of 1:3). The quantitative analysis of the samples was carried out by an Agilent 7890A gas chromatograph coupled with an Agilent 5975C Mass Selective detector. During the measurements, a Restek Rxi-1MS column was used $(30 \mathrm{~m} \times 0.25 \mathrm{~mm} \times 0.25 \mathrm{~mm})$. Three analytical standards, 2,4-toluenediamine, 2,4-dinitrotoluene, and 2-methyl-5-nitroaniline (Sigma Aldrich Ltd., Steinheim, Germany) were used in the analysis of the samples. The presence and structure of the intermediates were deduced from the data contained in the NIST 08, NIST Mass Spectral Library.

\subsection{Catalytic Tests}

The prepared chromium(IV)-oxide-supported catalysts were compared in the catalytic hydrogenation of 2,4-dinitrotoluene (DNT). The Büchi Uster Picoclave reactor with a $200 \mathrm{~mL}$ stainless steel vessel and heating jacket was used for the tests. Hydrogen pressure was regulated and kept at $20 \mathrm{bar}$, and the reaction was carried out at $303,313,323$, and 333 K. Samples were collected after 5, 10, 15, 20, 30, 40, 60, 120, 180, and $240 \mathrm{~min}$. The initial concentration of 2,4-dinitrotoluene was $40 \mathrm{mmol} \mathrm{L}^{-1}$ in methanol. Only $0.1 \mathrm{~g}$ of catalyst was added to $150 \mathrm{~mL}$ of DNT solution. In order to check the catalyst stability, reusability tests were also carried out four times without regeneration.

The concentrations of the main product (TDA), the detected by-products and intermediates were measured by using an Agilent 7890A gas chromatograph coupled with an Agilent 5975C Mass Selective detector. The TDA formation was followed by applying a set of analytical standards (2,4-dinitrotoluene, 2,4-diaminotolune, 2-methyl-5-nitroaniline, 2methyl-3-nitroaniline, 4-methyl-3-nitroaniline, and 4-methyl-2-nitroaniline, Sigma Aldrich Ltd., Steinheim, Germany). The efficiency of the catalysts was defined by calculating the conversion $(X \%)$ of DNT based on the following equation (Equation (1)):

$$
X \%=\frac{\text { consumed } n_{D N T}}{\text { initial } n_{D N T}} \times 100
$$

The TDA yield (Y\%) in case of the catalysts was also calculated (Equation (2)):

$$
Y \%=\frac{n_{\text {formed TDA }}}{n_{\text {theoritical TDA }}} \times 100
$$

By assuming that the hydrogenation process is a first-order reaction, based on the initial and measured DNT concentrations $\left(c_{0}\right.$ and $\left.c_{k}, \mathrm{~mol} / \mathrm{dm}^{3}\right)$, the reaction rate constant $(k)$ was calculated at different temperatures by applying non-linear regression (Figure 4 ) as follows (Equation (3)):

$$
c_{k}=c_{0} \times \exp (-k \times t)
$$

Turnover numbers (TON) were also calculated after $60 \mathrm{~min}$ of hydrogenation to compare the activities of the catalysts based on the follow equation (Equation (4)):

$$
T O N=\frac{n_{T D A}}{n_{\text {catalyst }}}
$$

where $n_{T D A}$ is the number of moles of the formed TDA and $n_{\text {catalyst }}$ is the amount of the applied precious metal. 
The activation energies $(E a)$ were calculated based on the Arrhenius equation by non-linear regression using (Equation (5)):

$$
k=A \times \exp \left[-\left(\frac{E a}{R \times T}\right)\right]
$$

\section{Conclusions}

A fast, efficient, and easy catalyst preparation method was developed to produce magnetic chromium(IV) dioxide nanowires that supported palladium and platinum catalysts. The catalysts showed high catalytic activity in the hydrogenation of 2,4-dinitrotoluene. TDA yields were $99.7 \mathrm{n} / \mathrm{n} \%\left(\mathrm{Pt} / \mathrm{CrO}_{2}\right)$ and $98.8 \mathrm{n} / \mathrm{n} \%\left(\mathrm{Pd} / \mathrm{CrO}_{2}\right)$ at $333 \mathrm{~K}$ and $20 \mathrm{bar}$ hydrogen pressure. By GC-MS investigations, trace amounts of side-products were also detected, some of which turned out to be imine derivatives. The imine bonds can be formed via the reaction of the aromatic amines and the methyl group of the other toluene derivative. Based on our experimental results, a possible mechanism for the formation of TDA and the detected side-products was proposed. These findings indicate that, by altering the reaction conditions, our catalysts may be used for the preparation of imines and/or amines by the direct reaction of $\mathrm{C}-\mathrm{H}$ bonds and amines. Turnover numbers (TONs) were calculated after one hour of hydrogenation, and, in the case of the $\mathrm{Pt} / \mathrm{CrO}_{2}$ catalyst $304.8 \mathrm{~mol}$ of TDA was formed, whereas in the case of the $\mathrm{Pd} / \mathrm{CrO}_{2}$ catalyst, only $60.14 \mathrm{~mol}$ TDA was formed, considering $1 \mathrm{~mol}$ of precious metal at $333 \mathrm{~K}$ and 20 bar.

In summary, excellent magnetic $\mathrm{Pd} / \mathrm{CrO}_{2}$ and $\mathrm{Pt} / \mathrm{CrO}_{2}$ catalysts were achieved and successfully tested in a commercially important hydrogenation reaction. For commercial applications, one of the biggest advantages of these catalysts is their easy and fast preparation, which could reduce catalyst cost. They were well dispersible in the reaction media (methanolic solution of DNT), resulting in a remarkable catalytic activity. In addition, the $\mathrm{CrO}_{2}$ magnetic support eliminates the inherent separation issue of nano-formulated catalyst particles. The prepared catalysts can be removed from the medium quickly and completely by using an external magnetic field, which may significantly reduce catalyst loss and, as a result, the production cost. The catalysts can be reused at least four times without regeneration, and GC-MS analysis of the reaction mixture suggests that, by altering the reaction conditions, carbon-nitrogen bonds can also be formed, making these nanoparticles multifunctional catalysts.

Supplementary Materials: The following are available online at https:/ /www.mdpi.com/article/10 $.3390 /$ ijms22115945/s1.

Author Contributions: Methodology, writing—original draft preparation, V.H.; methodology, G.M., T.F., and I.K.; data curation, G.M., A.J.-N.; writing-reviewing and editing, B.F.; validation, funding acquisition, B.V. and M.N.; conceptualization, supervision, L.V. All authors have read and agreed to the published version of the manuscript.

Funding: This research was supported by the European Union and the Hungarian State and cofinanced by the European Regional Development Fund in the framework of the GINOP-2.3.4-15-201600004 project, which aims to promote the cooperation between the higher education and the industry.

Institutional Review Board Statement: Not applicable.

Informed Consent Statement: Not applicable.

Data Availability Statement: Data is available upon request from the corresponding authors.

Acknowledgments: B.F. thanks the support of the ÚNKP-20-4 New National Excellence Program of The Ministry for Innovation and Technology from the source of the National Research, Development and Innovation Fund.

Conflicts of Interest: The authors declare no conflict of interest. 


\section{References}

1. Neri, G.; Musolino, M.G.; Milone, C.; Visco, A.M.; Di Mario, A. Mechanism of 2,4-dinitrotoluene hydrogenation over Pd/C. J. Mol. Catal. A Chem. 1995, 95, 235-241. [CrossRef]

2. Neri, G.; Musolino, M.G.; Rotondo, E.; Galvagno, S. Catalytic hydrogenation of 2,4-dinitrotoluene over a Pd/C catalyst: Identification of 2-(hydroxyamino)-4-nitrotoluene (2HA4NT) as reaction intermediate. J. Mol. Catal. A Chem. 1996, 111, 257-260. [CrossRef]

3. Musolino, M.G.; Neri, G.; Milone, C.; Minicò, S.; Galvagno, S. Liquid chromatographic separation of intermediates of the catalytic hydrogenation of 2,4-dinitrotoluene. J. Chromatogr. A 1998, 818, 123-126. [CrossRef]

4. Neri, G.; Musolino, M.G.; Milone, C.; Pietropaolo, D.; Galvagno, S. Particle size effect in the catalytic hydrogenation of 2,4dinitrotoluene over Pd/C catalysts. Appl. Catal. A Gen. 2001, 208, 307-316. [CrossRef]

5. Neri, G.; Rizzo, G.; Milone, C.; Galvagno, S.; Musolino, M.G.; Capannelli, G. Microstructural characterization of doped-Pd/C catalysts for the selective hydrogenation of 2,4-dinitrotoluene to arylhydroxylamines. Appl. Catal. A Gen. 2003, 249, 303-311. [CrossRef]

6. Saboktakin, M.R.; Tabatabaie, R.M.; Maharramov, A.; Ramazanov, M.A. Hydrogenation of 2,4-Dinitrotoluene to 2,4-Diaminotoluene over Platinum Nanoparticles in a High-Pressure Slurry Reactor. Synth. Commun. 2011, 41, 1455-1463. [CrossRef]

7. Pinna, F.; Selva, M.; Signoretto, M.; Strukul, G.; Boccuzzi, F.; Benedetti, A.; Canton, P.; Fagherazzi, G. Pd-Fe/SiO 2 Catalysts in the Hydrogenation of 2,4-Dinitrotoluene. J. Catal. 1994, 150, 356-367. [CrossRef]

8. Benedetti, A.; Fagherazzi, G.; Pinna, F.; Rampazzo, G.; Selva, M.; Strukul, G. The influence of a second metal component (Cu, Sn, $\mathrm{Fe}$ ) on $\mathrm{Pd} / \mathrm{SiO}_{2}$ activity in the hydrogenation of 2,4-dinitrotoluene. Catal. Lett. 1991, 10, 215-223. [CrossRef]

9. Molga, E.J.; Westerterp, K.R. Kinetics of the hydrogenation of 2,4-dinitrotoluene over a palladium on alumina catalyst. Chem. Eng. Sci. 1992, 47, 1733-1749. [CrossRef]

10. Rajashekharam, M.V.; Nikalje, D.D.; Jaganathan, R.; Chaudhari, R.V. Hydrogenation of 2,4-Dinitrotoluene Using a Pd/ $\mathrm{Al}_{2} \mathrm{O}_{3}$ Catalyst in a Slurry Reactor: A Molecular Level Approach to Kinetic Modeling and Nonisothermal Effects. Ind. Eng. Chem. Res. 1997, 36, 592-604. [CrossRef]

11. Tsang, S.C.; Caps, V.R.; Paraskevas, I.; Chadwick, D.; Thompsett, D. Magnetically Separable, Carbon-Supported Nanocatalysts for the Manufacture of Fine Chemicals. Angew. Chem. 2004, 116, 5763-5767. [CrossRef]

12. Rossi, L.M.; Costa, N.J.S.; Silva, F.P.; Wojcieszak, R. Magnetic nanomaterials in catalysis: Advanced catalysts for magnetic separation and beyond. Green Chem. 2014, 16, 2906. [CrossRef]

13. Kainz, Q.M.; Linhardt, R.; Grass, R.N.; Vilé, G.; Pérez-Ramírez, J.; Stark, W.J.; Reiser, O. Palladium Nanoparticles Supported on Magnetic Carbon-Coated Cobalt Nanobeads: Highly Active and Recyclable Catalysts for Alkene Hydrogenation. Adv. Funct. Mater. 2014, 24, 2020-2027. [CrossRef]

14. Stadler, L.; Homafar, M.; Hartl, A.; Najafishirtari, S.; Colombo, M.; Zboril, R.; Martin, P.; Gawande, M.B.; Zhi, J.; Reiser, O. Recyclable Magnetic Microporous Organic Polymer (MOP) Encapsulated with Palladium Nanoparticles and Co/C Nanobeads for Hydrogenation Reactions. ACS Sustain. Chem. Eng. 2018, 7, 2388-2399. [CrossRef]

15. Purohit, G.; Rawat, D.S.; Reiser, O. Palladium Nanocatalysts Encapsulated on Porous Silica @ Magnetic Carbon-Coated Cobalt Nanoparticles for Sustainable Hydrogenation of Nitroarenes, Alkenes and Alkynes. ChemCatChem 2019, 12, 569-575. [CrossRef]

16. Ye, L.; Liu, X.; Lu, Y. A highly controllable, effective, and recyclable magnetic-nanoparticle-supported palladium catalyst for the Suzuki-Miyaura cross-coupling reaction. J. Catal. 2021, 397, 36-43. [CrossRef]

17. Bogdal, D.; Lukasiewicz, M.; Pielichowski, J.; Miciak, A.; Bednarz, S. Microwave-assisted oxidation of alcohols using Magtrieve ${ }^{\mathrm{TM}}$. Tetrahedron 2003, 59, 649-653. [CrossRef]

18. Ding, Y.; Yuan, C.; Wang, Z.; Liu, S.; Shi, J.; Xiong, R.; Yin, D.; Lu, Z. Improving thermostability of $\mathrm{CrO}_{2}$ thin films by doping with Sn. Appl. Phys. Lett. 2014, 105, 092401. [CrossRef]

19. West, K.G.; Osofsky, M.; Mazin, I.I.; Dao, N.N.H.; Wolf, S.A.; Lu, J. Magnetic properties and spin polarization of Ru doped half metallic $\mathrm{CrO}_{2}$. Appl. Phys. Lett. 2015, 107, 012402. [CrossRef]

20. Solovyev, I.V.; Kashin, I.V.; Mazurenko, V.V. Mechanisms and origins of half-metallic ferromagnetism in CrO 2 . Phys. Rev. B 2015, 92, 9664-9670. [CrossRef]

21. Duarte, A.C.; Franco, N.; Viana, A.S.; Polushkin, N.I.; Silvestre, A.J.; Conde, O. Argon assisted chemical vapor deposition of $\mathrm{CrO}_{2}$ : An efficient process leading to high quality epitaxial films. J. Alloy. Compd. 2016, 684, 98-104. [CrossRef]

22. Anger, G.; Halstenberg, J.; Hochgeschwender, K.; Scherhag, C.; Korallus, U.; Knopf, H.; Schmidt, P.; Ohlinger, M. Chromium Compounds. In Ullmann's Encyclopedia of Industrial Chemistry; Wiley-VCH Verlag GmbH \& Co. KGaA: Weinheim, Germany, 2005; pp. 157-191.

23. Ko, K.-Y.; Kim, J.-Y. Generation of Diphenyldiazomethane by Oxidation of Benzophenone Hydrazone with Magtrieve TM. Bull. Korean Chem. Soc. 1999, 20, 771-772.

24. Wan, H.; Peng, Y. Clean synthesis of azo compounds using Magtrieve ${ }^{\mathrm{TM}}$ in the ionic liquid [bmim][Br]. Mon. für Chemie Chem. Mon. 2008, 139, 909-912. [CrossRef]

25. Liu, Y.-H. MagtrieveTM $\left(\mathrm{CrO}_{2}\right)$ : A Versatile Oxidant in Organic Synthesis. Synlett 2008, 2008, 1103-1104. [CrossRef]

26. Lee, R.A.; Donald, D.S. Magtrieve ${ }^{\mathrm{TM}}$ an efficient, magnetically retrievable and recyclable oxidant. Tetrahedron Lett. 1997, 38, 3857-3860. [CrossRef]

27. Few, C.S.; Williams, K.R.; Wagener, K.B. Magtrieve ${ }^{\mathrm{TM}}$ : A convenient catalyst for the oxidation of alcohols. Tetrahedron Lett. 2014, 55, 4452-4454. [CrossRef] 
28. Prekob, Á.; Muránszky, G.; Kocserha, I.; Fiser, B.; Kristály, F.; Halasi, G.; Kónya, Z.; Viskolcz, B.; Vanyorek, L. Sonochemical Deposition of Palladium Nanoparticles Onto the Surface of N-Doped Carbon Nanotubes: A Simplified One-Step Catalyst Production Method. Catal. Lett. 2019, 150, 505-513. [CrossRef]

29. Hajdu, V.; Prekob, Á.; Muránszky, G.; Kocserha, I.; Kónya, Z.; Fiser, B.; Viskolcz, B.; Vanyorek, L. Catalytic activity of maghemite supported palladium catalyst in nitrobenzene hydrogenation. React. Kinet. Mech. Catal. 2020, 129, 107-116. [CrossRef]

30. Suslick, K.S. Sonochemistry. In Kirk-Othmer Encyclopedia of Chemical Technology; John Wiley \& Sons, Inc.: Hoboken, NJ, USA, 2000.

31. Feng, Q.X.; Jie, Z.J. Synthesis of Palladium Nanoparticles by A Sonochemical Method. Chin. J. Inorg. Chem. 2003, 19, 766-770.

32. Qiu, X.-F.; Zhu, J.-J.; Chen, H.-Y. Controllable synthesis of nanocrystalline gold assembled whiskery structures via sonochemical route. J. Cryst. Growth 2003, 257, 378-383. [CrossRef]

33. Ying, Y.; Qi-Yun, Z.; Xing-Guo, L. Reduction Process of Transition Metal Ions by Zinc Powder to Prepare Transition Metal Nanopowder. Acta Phys. Chim. Sin. 2003, 19, 436-440. [CrossRef]

34. Wu, S.-H.; Chen, D.-H. Synthesis and characterization of nickel nanoparticles by hydrazine reduction in ethylene glycol. J. Colloid Interface Sci. 2003, 259, 282-286. [CrossRef]

35. Wang, C.; Yang, F.; Yang, W.; Ren, L.; Zhang, Y.; Jia, X.; Zhang, L.; Li, Y. PdO nanoparticles enhancing the catalytic activity of $\mathrm{Pd} /$ carbon nanotubes for 4-nitrophenol reduction. RSC Adv. 2015, 5, 27526-27532. [CrossRef]

36. Neri, G.; Musolino, M.G.; Milone, C.; Galvagno, S. Kinetic Modeling of 2,4-Dinitrotoluene Hydrogenation over Pd/C. Ind. Eng. Chem. Res. 2002, 34, 2226-2231. [CrossRef]

37. Malyala, R.V.; Chaudhari, R.V. Hydrogenation of 2,4-Dinitrotoluene Using a Supported Ni Catalyst: Reaction Kinetics and Semibatch Slurry Reactor Modeling. Ind. Eng. Chem. Res. 1999, 38, 906-915. [CrossRef]

38. Brandt, A.; RanguMagar, A.B.; Szwedo, P.; Wayland, H.A.; Parnell, C.M.; Munshi, P.; Ghosh, A. Highly economical and direct amination of sp3 carbon using low-cost nickel pincer catalyst. RSC Adv. 2021, 11, 1862-1874. [CrossRef]

39. Pang, S.; Yuan, H.-K.; Wu, Y.; Shi, F. In Co@N-graphene/C Catalyzed Oxidative Amination of Toluene Derivatives. J. Mol. Catal. 2017, 31, 105-120. 